\title{
Characterizing circulating nucleosomes in the plasma of dogs with hemangiosarcoma
}

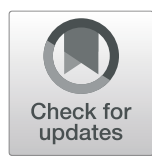

Heather Wilson-Robles ${ }^{1 *}$, Tasha Miller ${ }^{1}$, Jill Jarvis ${ }^{1}$, Jason Terrell ${ }^{2}$, Theresa Kathleen Kelly ${ }^{1,2}$, Thomas Bygott ${ }^{3}$ and Mhammed Bougoussa ${ }^{4}$

\begin{abstract}
Background: Nucleosomes consist of DNA wrapped around a histone octamer core like thread on a spool to condense DNA as chromatin into chromosomes. Diseases such as cancer or inflammation lead to cell death, chromatin fragmentation and release of nucleosomes into the blood. The Nu. $\mathrm{Q}^{\mathrm{TM}}$ platform measures circulating nucleosomes in the blood of humans that result from disease and has been used to detect and identify cancer even at early stages. The objectives of this study are to quantify and better characterize nucleosomes in dogs with various stages of hemangiosarcoma (HSA) using this ELISA-based assay.

Samples from 77 dogs with a confirmed diagnosis of hemangiosarcoma and 134 healthy controls were utilized for this study. The HSA samples were recruited from the Texas A\&M University Small Animal Clinic (TAMU-SAC) or purchased from biobanks. All control samples were recruited from the TAMU-SAC.

Results: Dogs with hemangiosarcoma had a 6.6-fold increase in their median plasma nucleosome concentrations compared to controls (AUC 92.9\%). Elevated nucleosome concentrations were seen at all stages of disease and nucleosome concentrations increased with the stage of the disease.

Conclusions: Plasma nucleosome concentrations are a reliable way to differentiate dogs with hemangiosarcoma from healthy dogs. Further testing is underway to better characterize cancer associated HSA circulating nucleosomes and optimize future diagnostics for canine HSA detection.
\end{abstract}

Keywords: Hemangiosarcoma, Dog, Canine, Nucleosome, H3.1, Cell free DNA, Plasma, H3

\section{Introduction}

Liquid biopsy (LB) techniques refer to the minimally invasive approach of sampling tumor specific biomarkers in the blood of diseased patients [1]. LB has been most studied in the field of oncology; however, literature also exists on the use of LB for the prognostication of inflammation, sepsis and trauma in humans and dogs [2-5]. In general, LB techniques are used to identify intact circulating tumor cells, extracellular nucleic acids such as cell free DNA (cfDNA), messenger RNA (mRNA), microRNA (miRNA), extracellular vesicles (exosomes),

\footnotetext{
* Correspondence: hwilson@cvm.tamu.edu

${ }^{1}$ College of Veterinary Medicine, Small Animal Clinical Sciences Department, Texas A\&M University, College Station, TX 77843, USA

Full list of author information is available at the end of the article
}

nucleosomes and glycoproteins or antigens in the circulation (e.g. PSA, CEA, CA125) [1].

The detection of cfDNA in the blood of cancer patients is a rapidly emerging field in cancer diagnostics [6]. These techniques allow for the minimally invasive detection of cancer DNA as an adjunct or even as an alternative to standard biopsy approaches. cfDNA can be found in the cell free component of the blood and is typically in fragments that are 120-200 bp long [6]. This cfDNA is often released into the bloodstream through apoptosis or necrosis, therefore, healthy individuals typically have low levels of cfDNA in their plasma [4, 7]. Plasma concentrations of cfDNA are also very dynamic as these fragments are often cleared from the plasma within an hour [4, 7]. Many conditions can influence

(c) The Author(s). 2021 Open Access This article is licensed under a Creative Commons Attribution 4.0 International License, which permits use, sharing, adaptation, distribution and reproduction in any medium or format, as long as you give appropriate credit to the original author(s) and the source, provide a link to the Creative Commons licence, and indicate if changes were made. The images or other third party material in this article are included in the article's Creative Commons licence, unless indicated otherwise in a credit line to the material. If material is not included in the article's Creative Commons licence and your intended use is not permitted by statutory regulation or exceeds the permitted use, you will need to obtain permission directly from the copyright holder. To view a copy of this licence, visit http://creativecommons.org/licenses/by/4.0/ The Creative Commons Public Domain Dedication waiver (http://creativecommons.org/publicdomain/zero/1.0/) applies to the data made available in this article, unless otherwise stated in a credit line to the data. 
plasma concentrations of cfDNA including cancer, heavy exercise, inflammation, surgery or tissue injury [8].

Nucleosomes are a particular form of cfDNA released during apoptosis or necrosis in a variety of diseases. They are small fragments of chromosomes that are composed of a 147 bp segment of DNA wrapped around a histone core made of four histones present in duplicate forming an octamer [9]. Nucleosomes have been used as epigenetic biomarkers for the detection or monitoring of a variety of cancers in humans including pancreatic, lung, and colorectal cancer [10-13]. Letendre et al. published some of the first work describing the use of nucleosomes in dogs with trauma and sepsis in 2018 [14, 15]. Recently, our group published data demonstrating elevated nucleosome concentrations in a small cohort of dogs with lymphoma [16]. However, the nucleosome compartment is a relatively uninvestigated area of circulating tumor biomarkers in dogs.

The purpose of this study was to determine if dogs with hemangiosarcoma (HSA), an aggressive mesenchymal tumor derived from malignant endothelial cell precursors, demonstrated elevated concentrations of plasma nucleosomes when compared to healthy dogs [17]. HSA is a devastating disease of dogs and represents $12-21 \%$ of the mesenchymal tumors in this species $[18,19]$. This cancer is characterized by rapid progression and early metastasis with a one-year survival rate of $<10 \%$ [20-23]. The most common primary tumor site is the spleen with HSA representing $45-51 \%$ of all splenic malignancies in dogs $[20,21]$. The most common presenting complaint for this disease is acute hypovolemic shock due to a spontaneous bleeding episode, however, splenic masses may be found incidentally in many older dogs. For these reasons, HSA is a prime candidate for the development of non-invasive liquid biopsy diagnostics as it would enable a non-invasive cancer screening method that would prevent unnecessary exploratory surgeries which have associated morbidities.

\section{Results}

\section{Canine patient characteristics}

A total of 134 healthy dogs were recruited for this study ranging in age from 10 months to 14 years (median 6 years). Forty-eight of the 134 dogs were aged 7 years or older (35.8\%). The healthy control cohort had a male to female ratio of 1.05 and a sex distribution including 4 intact females, spayed females $(n=61)$, intact males $(n=3)$, and castrated males $(n=$ $65)$. The mean body weight for all healthy dogs was $23 \mathrm{~kg}$ (range 2.5 to $55.8 \mathrm{~kg}$ ). The majority of these dogs were mixed breed dogs $(29 / 134,21.6 \%)$. Other common breeds included Labrador retriever $(n=15)$, Australian cattle $\operatorname{dog}(n=10)$, pit bull terrier $(n=7)$, border collie $(n=6)$, golden retriever $(n=5)$, dachshund $(n=4)$, and German shepherd $(n=3)$.

There was a total of 77 dogs in the HSA cohort. These dogs ranged in age from 4 to 15 years (median age 10 years). There were 33 spayed females $(42.9 \%), 2$ intact females (2.6\%), 33 neutered males (42.9\%) and 9 intact males $(11.7 \%)$ in this cohort. The majority of these dogs were also mixed breed dogs $(23 / 77,29.9 \%)$. Other common breeds in this cohort included golden retrievers (10/77, $13 \%)$, German Shepherd Dogs (5/77, $6.5 \%)$, Labrador retrievers $(4 / 77,5.2 \%)$ and 3 Boxers $(3.9 \%)$. The remaining dog breeds contained two or fewer patients or were undefined. As expected, the majority of the dogs in this cohort presented with primary splenic HSA (53/77, $68.8 \%)$. Other common sites included the right atrium (7/77, 9.1\%) and bone (5/77, 6.5\%), primary renal (5/77, $6.5 \%)$, subcutaneous/cutaneous $(5 / 77,6.5 \%)$ and 1 each primary hepatic and skin tumors $(1 / 77,1.3 \%)$. HSA was confirmed via histopathology in all 77 cases. Tumor stage was available for 64 of the dogs in this cohort. There were 9 dogs with stage I disease (13.8\%), 25 of the cases were considered stage II (38.5\%) and 30 were considered stage III (40.0\%) at diagnosis.

\section{Nucleosome concentrations are elevated in dogs with HSA}

Total H3.1 nucleosome concentrations were measured in duplicate for all cases. The median nucleosome concentration for the healthy dogs was $31.1 \mathrm{ng} / \mathrm{mL}$ (mean $32.1 \mathrm{ng} /$ $\mathrm{mL}, \mathrm{SEM}$ 1.1). The dogs with confirmed HSA had a 6.6fold increase in the median nucleosome concentration at $204.6 \mathrm{ng} / \mathrm{mL}$ (mean $420.0 \mathrm{ng} / \mathrm{mL}$, SEM 53.6, $p<0.0001$ ) when compared to the healthy dogs (Fig. 1). A receiver operator characteristic (ROC) curve was generated using these data and the area under the curve (AUC) was calculated to be $92.9 \%$. For a specificity of $100 \%$ the cut off for the healthy range was set at $67.5 \mathrm{ng} / \mathrm{mL}$ (nucleosome range for all healthy dogs was $6.3-67.4 \mathrm{ng} / \mathrm{mL}$ ). At this concentration, the sensitivity of this assay was $80.5 \%$ and the specificity was $100 \%$ (Fig. 2).

\section{Elevated nucleosome concentrations vary by location in dogs with HSA}

Plasma nucleosome concentrations were evaluated for those locations with at least five cases each (Fig. 3). The median nucleosome concentration for dogs with primary splenic HSA regardless of stage was $214.8 \mathrm{ng} / \mathrm{mL}(n=$ 53, mean $461.6 \mathrm{ng} / \mathrm{mL}$, SEM 69.4, $p<0.0001)$. For dogs with primary cardiac HSA the median nucleosome concentration was $129.9 \mathrm{ng} / \mathrm{mL}(n=7$, mean $300.9 \mathrm{ng} / \mathrm{mL}$, SEM 172.9, $p=0.0001$. For those with primary osseous HSA the median nucleosome concentration was 592.8 $\mathrm{ng} / \mathrm{mL}(n=5$, mean $549.8 \mathrm{ng} / \mathrm{mL}$, SEM 191.5, $p=$ 0.00015 . Though the median nucleosome concentration 


\section{Elevated Nucleosome Levels in Hemangiosarcoma (HSA)}

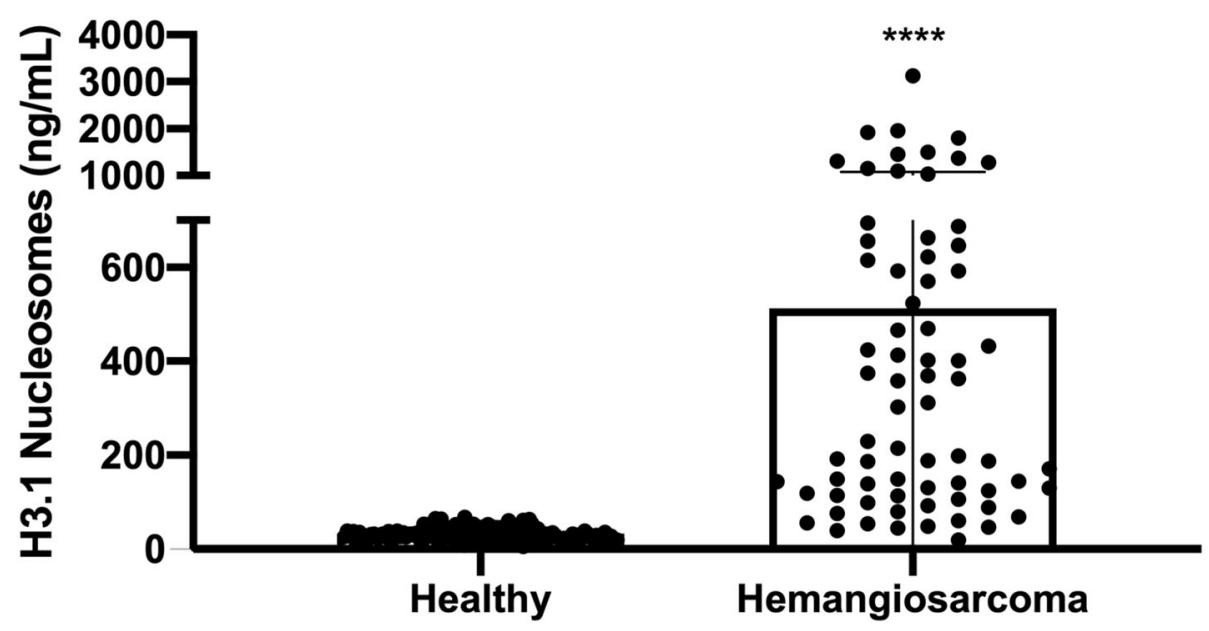

Fig. 1 Mean nucleosome concentrations in the plasma of healthy dogs and dogs with HSA

for dogs with subcutaneous HSA was high, this group was not significantly different from the healthy cohort $(n=5$, median $331.0 \mathrm{ng} / \mathrm{mL}$, mean $331.0 \mathrm{ng} / \mathrm{mL}$, SEM $184.8, p=0.904)$. The group with the lowest median nucleosome concentration were those with primary renal HSA ( $n-=5$, median $55.5 \mathrm{ng} / \mathrm{mL}$, mean $115 \mathrm{ng} / \mathrm{mL}$, SEM $72.2, p=0.068$. With the designated cut off of $67.5 \mathrm{ng} /$ $\mathrm{mL}$ the test was able to positively predict HSA in $47 / 53$ $(88.7 \%)$ cases of splenic HSA, 5/7 (71.4\%) primary cardiac HSA cases, 5/5 (100\%) primary bone HSA cases, 3/ $5(60 \%)$ primary SQ HSA cases and 1/5 (20\%) primary renal HSA cases.

Elevated nucleosome concentrations are seen in all three stages of HSA

The 64 dogs with HSA for whom staging information was available were assessed to determine if nucleosome concentrations could be used to identify those with early stage disease. Using the previously determined healthy range cut off of $67.5 \mathrm{ng} / \mathrm{mL}$, the assay was able to detect 6 of 9 cases with stage I disease (66.7\%), 19/25 cases with stage II disease (76\%) and 27 of 30 cases with stage III disease (90\%). Interestingly, the 2 stage III dogs not detected by the assay both had primary renal HSA. Median nucleosome concentrations increased with the stage of disease. The median nucleosome concentration for dogs with stage I disease was $124.2 \mathrm{ng} / \mathrm{mL}$ (mean 276.3 ng/mL, SEM 122.3, $p=0.04$, AUC $78.7 \%$ ). The median nucleosome concentration for dogs with stage II disease was $144 \mathrm{ng} / \mathrm{mL}$ (mean $361.6 \mathrm{ng} / \mathrm{mL}$, SEM 100.8, $p<$ 0.0001 , AUC 92.9\%) and the median plasma concentration for dogs with stage III disease was $413.1 \mathrm{ng} / \mathrm{mL}$ (mean 521.9 ng/mL, SEM 89.4, $p<0.0001$, AUC 95.7\%) (Fig. 4).

Nucleosome concentrations in dogs with HSA are not affected by age, sex or weight

All 77 dogs had a reported age and gender. Sixty-nine of the dogs had a reported body weight $(\mathrm{kg})$. Dogs with HSA were separated into 3 groups based on age (4-7 years $n=18,8-11$ years $n=39$ and $12-15$ years $n=20)$. All three age groups had significantly higher mean and median nucleosome concentrations than healthy dogs (Table 1). Dogs with HSA were separated into 4 groups based on gender (female spayed $n=33$, female intact $n=2$, neutered male $n=33$, and male intact $n=9$ ). There were too few cases in the female intact group for a meaningful comparison, however there were enough cases in the other groups for comparisons to be made (Table 2). Finally, dogs with HSA were separated into 4 groups based on weight. The 4 weight groups were < $15 \mathrm{~kg} n=5,15-30 \mathrm{~kg} n=25,30-45 \mathrm{~kg} n=34$, and > $45 \mathrm{~kg} n=5$. All groups had significantly higher median nucleosome concentrations except for the dogs $>45 \mathrm{~kg}$ $(p=0.057)$ than the control dogs, however, there were very few dogs in the $<15 \mathrm{~kg}$ and $>45 \mathrm{~kg}$ groups (Table 3). When compared to each other, there was no significant difference between the groups of HSA cases in any category ( $p>0.999$ for all comparisons).

Nucleosome concentrations are altered with response to therapy

Serial plasma samples from one dog with recurrent stage III HSA were evaluated throughout the course of 


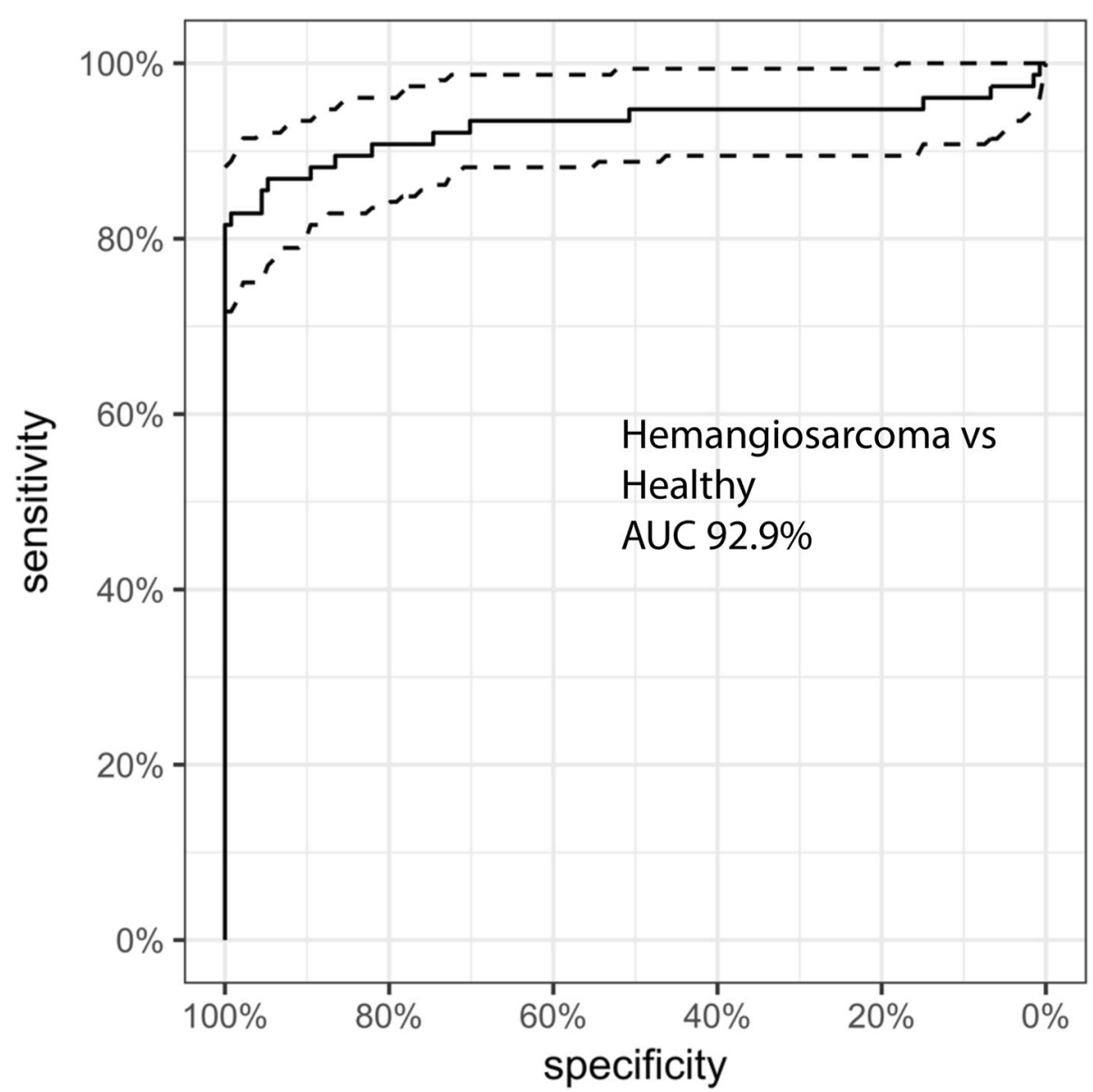

Fig. 2 ROC curve demonstrating the ability of the assay to discriminate between healthy dogs and those with HSA. The AUC for this assay was determined to be $92.9 \%$

treatment (Fig. 5). This patient was a 12-year-old MN Catahoula hog dog that had previously been diagnosed and treated for subcutaneous HSA in 2017. Through routine monitoring (whole body CT scan every 2-3 months) he was found to have progressive disease in April of 2019 with multiple pulmonary and intramuscular lesions as well as an intraseptal intracardiac lesion. Cytology on an intramuscular metastatic lesion was consistent with HSA and this was later confirmed at necropsy. This patient underwent several therapeutic interventions including stereotactic radio-body therapy, whole lung radiation, chemotherapy (doxorubicin, dacarbazine, chlorambucil and vinblastine), alpha- and betaadrenergic blockade and immunomodulatory therapy over the course of the next year. He was in clinical remission in January of 2020 until April of 2020 where progressive disease was noted once more on imaging. Interestingly, his plasma nucleosome concentrations began to increase in February, 2 months before progression was noted on imaging and remained high even though additional therapies were attempted. Unfortunately, the patient failed to respond to the additional therapies and was euthanized secondary to complications of central nervous system metastases at the end of May 2020. Necropsy confirmed widespread metastatic disease. Plasma samples were collected before progression was noted in October of 2018 and throughout treatment. These samples were processed according to predetermined optimal criteria and frozen at $-80 \mathrm{C}$ [16]. The samples were batched and all run together after the patient's death in conjunction with $C$ reactive protein (CRP) and thymidine kinase (TK) assays. Interestingly, plasma nucleosome concentrations reflect the clinical course of disease more accurately than CRP or TK, at least in this one patient. There is a spike in CRP noted with a small increase in nucleosome concentrations in 


\section{Nucleosome Concentration by HSA location}

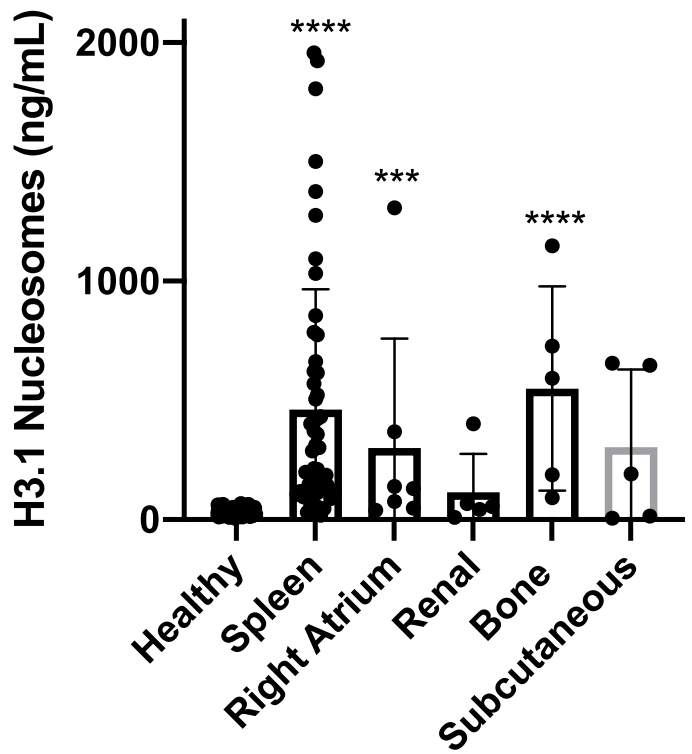

Fig. 3 Median nucleosome concentrations in dogs with HSA based on primary location. Dogs with primary splenic, cardiac and bone HSA had significantly higher median nucleosome concentrations than healthy dogs

May of 2020 for this patient which coincided with an episode of severe gastroenteritis that required ICU hospitalization for 2 days.

\section{Discussion}

HSA is a common mesenchymal malignancy often affecting larger breed dogs. This disease is characterized by a primary cavitated lesion in the viscera (spleen, heart, liver), muscular or subcutaneous tissue with a high propensity to spread early and often to other locations in the body such as the lungs, lymph nodes and other viscera $[20,21]$. Because this is a tumor of blood vessels, a sudden onset of hypovolemic shock due to acute spontaneous bleeding maybe the first clinical sign

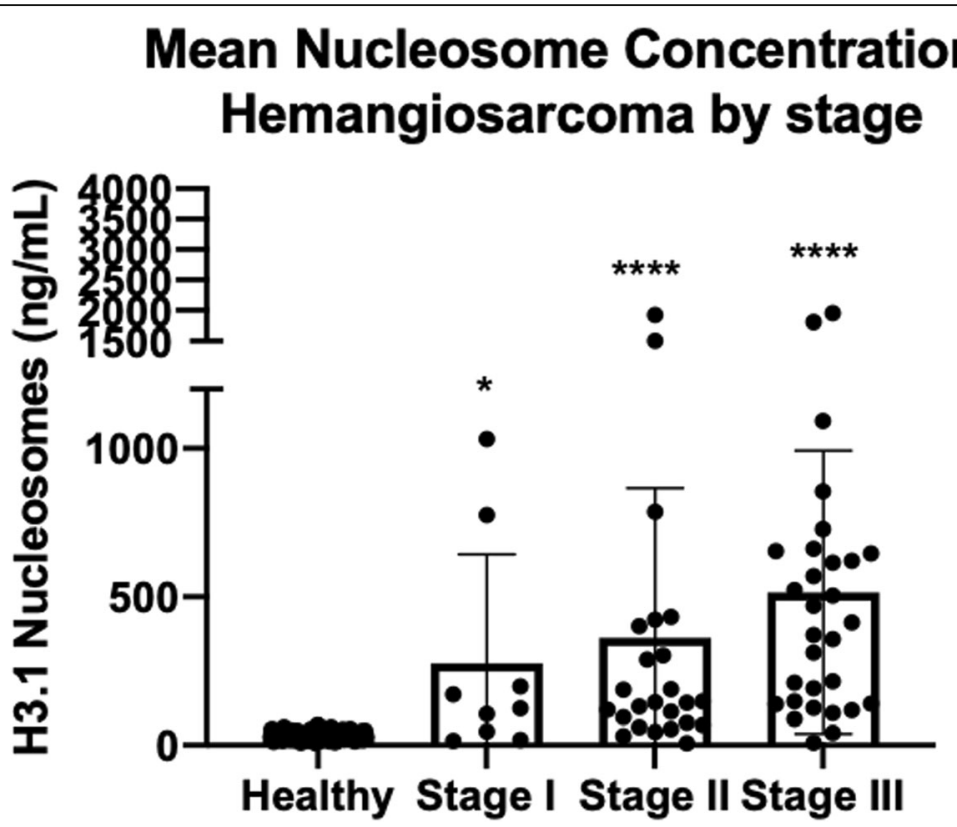

Fig. 4 Mean Nucleosome concentrations from dogs of all stages with HSA compared to healthy controls. The assay was able to detect $67 \%$ of dogs with stage I, $76 \%$ of dogs with stage II and $90 \%$ of dogs with stage III disease 
observed by the pet owner [24]. Non-invasive diagnostics may be highly suggestive of HSA; however, it is very difficult to collect cytologic or biopsy samples of these tumors without a surgical approach in many cases due to the fragility of the tumor and the extraordinary amount of blood flow the tumors possess [21, 25]. For this reason, new tests that can help direct client decision making without increasing the risk of acute hemorrhage are needed.

Though nucleosomes have DNA wrapped around them, they stand apart from other forms of circulating DNA through their pathophysiology. Nucleosomes play an active role in sepsis as part of neutrophil extracellular traps (NETs) which serve to remove extracellular pathogens from the blood [26]. In cancer, they are suspected to play a role in metastasis and injections of nucleosomes into mice with xenografts led to increased metastatic lesions and new tumor manifestations [27]. They have also been shown to enhance endothelial cell expression of interleukin 8 leading to neoangiogenesis in tumor tissue and ultimately tumor progression [28]. Finally, they have also been shown to play a role in tumor cell immune evasion by inhibiting natural killer cellmediated tumor lysis [29].

Though not specific for HSA, elevated nucleosome levels in the plasma of patients with HSA may provide additional information that can be useful to the client and veterinarian alike. In this cohort of 77 dogs, $80.5 \%$ of them (62 of 77) had mean plasma nucleosome concentrations above the $67.5 \mathrm{ng} / \mathrm{mL}$ designated cut off which is higher than the nucleosome levels of all 134 healthy dogs included in this study. A previously published manuscript evaluating the nucleosome compartment of healthy dogs determined that factors such as fasting, processing time, sample type and storage conditions can alter nucleosome concentrations in the plasma samples of healthy dogs [16]. For this reason, special care was taken in the selection and handling of these samples to ensure that all samples were handled the same way. When properly prepared, the plasma samples collected from normal dogs showed very little variability, similarly to what is seen in humans ${ }^{7}$.

The cohorts of both healthy dogs and those diagnosed with HSA were fairly diverse representing a variety of ages, breeds, body sizes and genders. However, nucleosome levels were unaffected by these factors (see supplement data). Only a diagnosis of HSA was able to differentiate between the two groups. Furthermore, the mean and median plasma nucleosome concentrations in the healthy dogs were surprisingly consistent across a variety of ages, body sizes and genders (supplement data) with SEMs $\leqq 5 \mathrm{ng} / \mathrm{mL}$ in all categories evaluated except body weight where dogs weighing more than $45 \mathrm{~kg}$ had an SEM of $14.7 \mathrm{ng} / \mathrm{mL}$. These data demonstrate that the nucleosome compartment is consistently low in healthy dogs across the board.

In this study nucleosome concentrations varied by location; however, these results should be viewed with caution for all locations except splenic HSA due to the low numbers of cases in the other groups. Interestingly, $100 \%(5 / 5)$ of the primary bone HSA cases were elevated. A study evaluating 48 cases of osteosarcoma (OSA) by this group demonstrated elevated nucleosome concentrations in only $17 / 48$ cases $(35 \%)$ with the highest levels in those cases with metastasis (data not shown). More cases of primary osseous HSA are needed; however, this assay may be able to differentiate HSA from OSA when it is localized to the bone.

Nucleosome concentrations are predictive of stage in humans in gastrointestinal cancer, while there is no correlation to stage for other cancer types [30]. In humans with lung and breast cancer, even the early stages of disease were found to have elevated serum nucleosome concentrations, similar to what was found here in dogs with HSA [31]. In the present study, elevated nucleosome concentrations were detected in $67 \%$ of dogs with stage I disease, $76 \%$ of dogs with stage II disease and $90 \%$ of dogs with stage III disease. This ability to detect early stage disease can be particularly useful as a screening test for older dogs by possibly detecting HSA before there is an acute bleeding episode.

Like most types of cfDNA, nucleosomes are cleared from the plasma quickly, usually within an hour [3, 4]. In healthy individuals' nucleosomes are often cleared within minutes through endonuclease degradation, immunocomplexing with anti-nucleosome antibodies, phagocytosis and lysosomal degradation, hepatic metabolism or direct excretion through the kidneys [4].

Table 1 Nucleosome concentrations in dogs with hemangiosarcoma separated by age

\begin{tabular}{lllll}
\hline & Control & $\mathbf{4 - 7}$ years & 8-11 years & 12-15 years \\
\hline Number of cases & 134 & 18 & 39 & 20 \\
Median & 31.1 & 140.7 & 210.9 & $\mathbf{2 1 4 . 1}$ \\
Mean & 32.1 & 366.2 & 408.1 & $\mathbf{4}$ \\
SEM & 1.1 & 94.8 & 74.3 & 122.1 \\
$P$ value (healthy comparison) & & $<0.0001$ & $<0.0001$ & $>0.0001$ \\
$P$ value (compared to other HSA groups) & & $>0.999$ & $>0.999$ & $>0.999$ \\
\hline
\end{tabular}


Table 2 Nucleosome concentrations in dogs with hemangiosarcoma separated by gender

\begin{tabular}{llllll}
\hline & Control & Female Spayed & Female Intact & Male Neutered & Male Intact \\
\hline Number of cases & 134 & 33 & 2 & 33 & 9 \\
Median & 31.1 & 258.8 & 185.3 & 187.5 & 148.6 \\
Mean & 32.1 & 408.1 & 185.3 & 473.4 & 318.4 \\
SEM & 1.1 & 74.3 & 44.6 & 96.7 & 101.4 \\
$P$ value (Healthy comparison) & & $<0.0001$ & 0.0158 & $>0.0001$ & $>0.0001$ \\
$P$ value (compared to other HSA groups) & & $>0.999$ & $>0.999$ & & $>0.999$ \\
\hline
\end{tabular}

However, in diseased patients, nucleosome elimination may be delayed when they bind to acute phase proteins [4]. Though cancer is not the only cause of elevated nucleosome concentrations in humans or dogs, the short half-life of this type of cfDNA can provide a real time window into the amount of apoptosis or cell turn over in that patient at any given time. Elevations in plasma nucleosomes have been used in humans for monitoring response to therapy or recovery in a variety of diseases such as autoimmune disease, cancer, sepsis, viral infections and trauma [3, 30, 32-34]. For this reason, plasma nucleosome concentrations may be a reliable and effective way to screen otherwise healthy canine patients at risk for HSA. Caution should be used; however, when evaluating plasma nucleosome concentrations of clinically ill dogs as nucleosomes are not specific for HSA or other common cancers.

Nucleosome concentrations have been used to monitor treatment response in rodents with HeLa xenografts as well as humans with cervical cancer and were found to reliably predict responders in both groups [35]. Circulating nucleosome concentrations went down significantly after one cycle of platinum-based chemotherapy in the women with cervical cancer who had measurable responses. In patients with acute myeloid leukemia undergoing induction chemotherapy, nucleosome concentrations were an early predictor of treatment responders [36]. Plasma nucleosome concentrations also correlated with response to therapy in patients with non-small cell lung cancer $[37,38]$. Here, we present a single case as a proof of concept that plasma nucleosome concentrations may serve as a surrogate for therapeutic response in patients with HSA. Though many more data points are needed before the utility of this test can be applied as a treatment monitoring tool for dogs with HSA, it is promising that nucleosome concentrations in dogs may mirror that which is seen in humans with a variety of cancers.

Other proteins, such as C-reactive protein (CRP) and Thymidine kinase have also been used to diagnose and monitor disease status in dogs with HSA. CRP is an acute phase protein that has been previously reported as a useful tool for evaluating remission status in canines with lymphoma and HSA [39-41]. Thymidine kinase is an enzyme involved in pyrimidine synthesis and increases in extracellular TK activity could indicate the overall degree of DNA synthesis and dying cells. TK has also been reported as a useful marker of remission status in canine lymphoma patients [39]. We evaluated both CRP and TK along with nucleosome concentrations in this patient as a proof of concept and found that CRP and TK values did not significantly change during the course of therapy and were not correlated with the clinical response in this one patient. Additional cases are needed to determine how effective nucleosomes concentrations are for disease monitoring when compared to CRP and TK.

\section{Conclusions}

Plasma nucleosome concentrations are an effective way to differentiate dogs with HSA from their healthy counterparts. Plasma nucleosome concentrations are fairly consistent in healthy dogs regardless of age, gender or

Table 3 Nucleosome concentrations in dogs with hemangiosarcoma separated by weight

\begin{tabular}{|c|c|c|c|c|c|}
\hline & Control & up to $15 \mathrm{~kg}$ & above 15 up to $30 \mathrm{~kg}$ & above 30 up to $45 \mathrm{~kg}$ & above $45 \mathrm{~kg}$ \\
\hline Number of cases & 134 & 5 & 25 & 34 & 5 \\
\hline Median & 31.1 & 129.9 & 132.1 & 212.9 & 113.7 \\
\hline Mean & 32.1 & 462.2 & 309.3 & 422.5 & 195.3 \\
\hline SEM & 1.1 & 336.2 & 61.8 & 79.7 & 74.6 \\
\hline$P$ value (healthy comparison) & & 0.00015 & $<0.0001$ & $<0.0001$ & 0.0126 \\
\hline$P$ value (compared to other HSS groups) & & $>0.999$ & $>0.999$ & $>0.999$ & $>0.999$ \\
\hline
\end{tabular}




\section{Patient 1: Trends in Nucleosome Concentrations During Treatment for HSA}

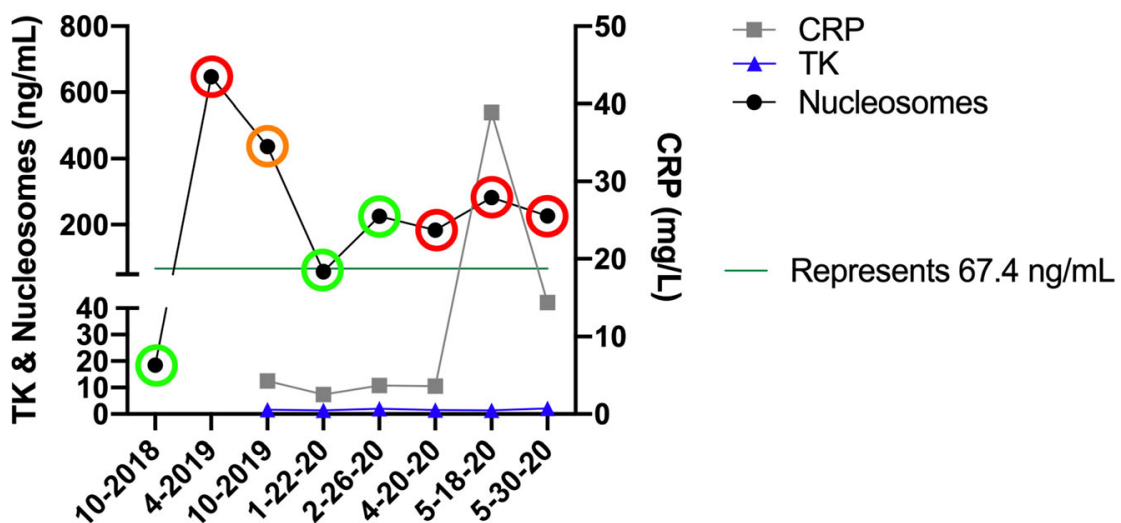

Fig. 5 Longitudinal assessment of nucleosome concentrations in a patient with stage III HSA throughout the course of treatment. The green circles represent clinical remission, red circles represent progressive disease and the orange circle represent a partial clinical response. All assessments were performed by a board-certified veterinary medical oncologist. All imaging was interpreted by a board-certified veterinary radiologist

body size (supplement data) and elevated nucleosome concentrations were seen even in early stage disease in over $80 \%$ of the patients evaluated. Common signalment characteristics did not affect nucleosome concentrations in dogs with HSA when compared to healthy dogs. Measuring circulating nucleosome levels provides significant promise as a non-invasive tool for detecting HSA while limiting the likelihood for complications that are common with vascular tumors.

\section{Materials and methods}

\section{Animal samples}

All animal studies were approved by the Texas A\&M University Institutional Animal Care and Use Committee (AUP\# 2019-0211 and AUP\# 2017 -0350). Additional samples were purchased from the National Cancer Institute Division of Cancer Treatment and Diagnosis (NCI-DCTD) biospecimen repository. A total of 134 healthy dog volunteers were recruited from TAMU-SAC staff and client pets. A total of 77 samples from dogs with confirmed HSA were also recruited or purchased for this study. Informed consent was obtained from all pet owners before participation in the study.

\section{Sample collection and processing}

All blood samples were collected from a peripheral or jugular vein using standard blood collection techniques. All dogs were fasted for a minimum of $6 \mathrm{~h}$ before samples were collected. A total of 3-5 mL (depending on the size of the dogs) were placed in EDTA primed (lavender top) tubes (Becton, Dickinson and Company, Franklin Lakes, NJ). Samples were centrifuged within one hour of collection at room temperature at $3000 \mathrm{xg}$ for $10 \mathrm{~min}$ [16]. Plasma was then immediately removed without disrupting the buffy coat layer, placed in prelabeled cryovials and frozen at $-80{ }^{\circ} \mathrm{C}$ to run in batches. All samples were run in duplicate.

All samples were tested using the Nu. $Q^{\mathrm{ma}} \mathrm{H} 3.1$ assay (Belgian Volition, SRL, Isnes, Belgium). This enzymelinked immunosorbent assay (ELISA) contains a capture antibody directed at histone 3.1 and a nucleosome specific detection antibody [42]. Frozen samples were thawed and allowed to come to room temperature for at least $30 \mathrm{~min}$ prior to analysis. Assays were performed according to the manufacturer's protocol. Briefly, a standard curve was generated using the positive control stock (recombinant H3.1 nucleosomes) provided. Samples were vortexed and centrifuged at $11,000 \mathrm{x} g$ for $3 \mathrm{~min}$ at $4{ }^{\circ} \mathrm{C}$. HSA samples were diluted 3 -fold to ensure that they could be measured within the detection limits of the assay. The nucleosomes were bound to the capture antibody and the plates were washed 3 times using $1 \mathrm{x}$ wash buffer. Twenty microliters of each diluted sample were pipetted in duplicate into wells on the 96 well plates. Next, $90 \mu \mathrm{L}$ of the assay buffer was added to each well. The plate was covered with sealing film and incubated on an orbital shaker for $2.5 \mathrm{~h}$ at $700 \mathrm{rpm}$. Plates were then emptied and washed 3 times using $1 \mathrm{x}$ washing buffer. Next, $100 \mathrm{uL}$ of the detection antibody was added to each well, the plate was resealed and incubated for $1.5 \mathrm{~h}$ on the orbital shaker. The plates were then washed as described above. Streptavidin HRP conjugate was incubated for $30 \mathrm{~min}$ in each well and washed before applying the colorimetric substrate solution and incubating 
the plates in the dark for $20 \mathrm{~min}$. A stop solution was added to the wells and the plates were read on a plate reader at $450 \mathrm{~nm}$ (BioTek Synergy H1 plate reader, BioTek Instruments, Winooski, VT). The standard curve was linearized and fitted to a 4-parameter logistic curve using statistical software (Graphpad Software, version 8, San Diego, CA).

One patient was followed longitudinally through his treatment protocol with serial sampling. C-reactive protein (CRP) and thymidine kinase (TK) were also measured on the samples collected at these appointments. The CRP assays were performed by the Texas A\&M University Gastrointestinal Laboratory and the TK assay was performed using the Canine Thymidine Kinase 1 soluble ELISA assay (My Biosource Inc, San Diego, CA) as long as sufficient sample was available to do so.

\section{CRP Assays}

For the longitudinally followed patient, samples were submitted to the Texas A\&M University Gastrointestinal Laboratory for c-reactive protein (CRP) assays if sufficient sample quantity was present. If sample quantity was not sufficient for both nucleosome and CRP analysis, nucleosome assays were given priority.

\section{Thymidine kinase assays}

The Canine Thymidine Kinase 1 soluble ELISA assay (MyBiosource Inc, San Diego, CA) was used to evaluate TK1 levels in the dog followed longitudinally. The assay was performed according to the manufacturer's protocol. Briefly, $40 \mu \mathrm{l}$ of sample was added to wells followed by $10 \mu \mathrm{l}$ anti-TK1 antibody. Then $50 \mu \mathrm{l}$ streptavidin-HRP was added to each well except the blank control well. The plate was mixed well, covered with sealer and incubated for $60 \mathrm{~min}$ at $37{ }^{\circ} \mathrm{C}$. The plate was then washed 5 times with wash buffer and the wells were soaked with at least $0.35 \mathrm{ml}$ wash buffer for $30 \mathrm{~s}$ to $1 \mathrm{~min}$ for each wash. Next $50 \mu \mathrm{l}$ of substrate solution A was added to each well followed by $50 \mu \mathrm{l}$ of substrate solution B to each well. The plate was covered with a fresh sealer for $10 \mathrm{~min}$ at $37^{\circ} \mathrm{C}$ in the dark. Finally, $50 \mu \mathrm{l}$ of Stop Solution was added to each well. Plates were read at an absorbance of 450nm (BioTek Synergy H1 plate reader, BioTek Instruments, Winooski, VT) within $10 \mathrm{~min}$ of stop solution being added. The standard curve was linearized and fitted to a 5-parameter logistic curve using statistical software (Graphpad Software, version 8, San Diego, CA).

\section{Intra and intergroup comparisons}

HSA samples were separated out by stage, age, weight and gender and compared used the statistical methods below. Stage I HSA is characterized by a solitary lesion that is $<5 \mathrm{~cm}$ in diameter, no evidence of hemorrhage and no evidence of metastasis (locoregional or distant) [43]. Stage II HSA is characterized by a lesion that is either $5 \mathrm{~cm}$ or greater or one that has ruptured with or without locoregional metastasis and no distant metastasis [43]. These tumors may also be invading into the subcutaneous tissues. Stage III HSA is characterized by highly invasive tumors with or without distant metastasis or tumors of any size with distant metastasis [43]. Age was divided into 4 groups: <3 years, $4-7$ years, 8-11 years and $>12$ years. Gender was also divided into 4 groups: spayed females, intact females, neutered males and intact males. Finally weight was also divided into 4 groups: $<15 \mathrm{~kg}, 15-30 \mathrm{~kg}, 30-45 \mathrm{~kg}$ and $>45 \mathrm{~kg}$.

\section{Statistical analysis}

Descriptive statistics for the patient populations were performed using Microsoft Excel for Mac (v. 16.16.27, 2016). For data sets containing only two cohorts, such as the healthy controls versus all HSA cases, a Wilcoxon rank sum test was used to compare the medians of the data sets. For data sets where multiple conditions were compared, such as disease stage, a two-way ANOVA for repeat measures with a Tukey's multiple comparisons test was performed. This part of the analysis was performed using GraphPad Prism version 8.0.0 for Macintosh, GraphPad Software, San Diego, California USA, www.graphpad.com. Wilcoxon rank sum tests, ROC curves and specificity/sensitivity calculations were performed using $\mathrm{R}$ version 3.4 .3 and the pROC package $[44,45]$.

\section{Abbreviations \\ AUC: Area under the curve; CA125: Cancer antigen 125; CEA: Carcinoembryonic antigen; cfDNA: Cell free deoxyribose nucleic acid; CRP: C-reactive protein; EDTA: Ethylenediaminetetraacetic acid; ELISA: Enzyme linked immunosorbent assay; HSA: Hemangiosarcoma; ICU: Intensive care unit; LB: Liquid biopsy; NCI-DCTD: National Cancer Institute Division of Cancer Treatment and Diagnosis; NETs: Neutrophil extracellular traps; PSA: Prostate specific antigen; ROC: Receiver operator characteristic; SEM: Standard error of mean; TK: Thymidine kinase}

\section{Supplementary Information}

The online version contains supplementary material available at https://doi. org/10.1186/s12917-021-02934-6.

\section{Additional file 1.}

\section{Acknowledgements}

The authors would like to acknowledge the Fred and Vola Palmer Chair in Comparative Oncology for funding support of this work.

\section{Authors' contributions}

Conceptualization: Heather Wilson-Robles. Data curation: Heather WilsonRobles, Tasha Miller, Jill Jarvis. Formal analysis: Heather Wilson-Robles, Theresa Kelly, Thomas Bygott, Mhammed Bougoussa. Funding acquisition: Heather Wilson-Robles, Jason Terrell. Investigation: Heather Wilson-Robles, Jill Jarvis. Methodology: Heather Wilson-Robles, Tasha Miller. Project administration: Heather Wilson-Robles, Jill Jarvis. Resources: Heather Wilson-Robles, Tasha 
Miller, Jill Jarvis, Jason Terrell, Theresa Kelly, Thomas Bygott, Mhammed Bougoussa. Software: Heather Wilson-Robles, Thomas Bygott, Mhammed Bougoussa. Supervision: Heather Wilson-Robles. Validation: Heather WilsonRobles, Tasha Miller. Visualization: Heather Wilson-Robles. Writing - original draft: Heather Wilson-Robles. Writing - review \& editing: All Authors. The author(s) read and approved the final manuscript.

\section{Authors' information}

Not applicable.

\section{Funding}

Funding for materials and author salaries was provided by Belgian Volition SRL. HWR and TM received salary from these funds. JT, TK, MB and TB are employees of Volition Diagnostics UK Ltd \& Volition America. The URL to the Volition website is: https://volition.com/. Some additional funding for HWR and TM salaries was provided by the Fred and Vola Palmer Chair of Comparative Oncology held by HWR.

\section{Availability of data and materials}

All relevant data are within the paper.

\section{Declarations}

\section{Ethics approval and consent to participate}

All animal studies were approved by the Texas A\&M University Animal Care and Use Committee (AUP \#2017 - 0350). Client-owned animals were evaluated with the informed consent of the owner (AUP \#2019 - 0211). 4) All methods were carried out in accordance with relevant guidelines and regulations.

No humans were involved in this study.

No agents were administered to dogs in any way during this study.

\section{Consent for publication}

Not applicable.

\section{Competing interests}

JT, TK, MB and TB are employees of Volition Diagnostics UK Ltd \& Volition America, which have patents covering Nu.Q technology and are developers of Nu.QTM assays. Volition Veterinary is a joint venture between Belgian Volition and Texas A\&M University. HWR is a paid consultant of Volition Veterinary. TM and JJ have no conflicts of interest to declare. Additional salary support for TM was provided by the Fred and Vola Palmer Chair in Comparative Oncology held by HWR. The Palmers did not play a role in the study design, data collection and analysis, decision to publish, or preparation of the manuscript and only provided financial support for the authors' salaries (T.M.). This does not alter our adherence to BMC policies on sharing data and materials.

\section{Author details}

${ }^{1}$ College of Veterinary Medicine, Small Animal Clinical Sciences Department, Texas A\&M University, College Station, TX 77843, USA. ${ }^{2}$ Volition America \& Volition Veterinary Diagnostic Development, 13215 Bee Cave Parkway, Galleria Oaks B, Suite 125, Austin, Texas 78738, USA. ${ }^{3}$ Volition Diagnostics UK Ltd, 93-95 Gloucester Place, London W1U 6JQ, UK. ${ }^{4}$ Belgian Volition SRL, 22 Rue Phocas Lejeune, Parc Scientifique Crealys, 5032 Isnes, Belgium.

Received: 8 March 2021 Accepted: 10 June 2021

Published online: 29 June 2021

\section{References}

1. Kustanovich A, Schwartz R, Peretz T, Grinshpun A. Life and death of circulating cell-free DNA. Cancer Biol Ther. 2019;20(8):1057-67.

2. Goggs R. Effect of sample type on plasma concentrations of cell-free DNA and nucleosomes in dogs. Vet Rec Open. 2019;6(1):e000357.

3. Holdenrieder S, Stieber P. Clinical use of circulating nucleosomes. Crit Rev Clin Lab Sci. 2009;46(1):1-24.

4. Holdenrieder S, Nagel D, Schalhorn A, Heinemann V, Wilkowski R, von Pawel $J$, et al. Clinical relevance of circulating nucleosomes in cancer. Ann N Y Acad Sci. 2008;1137:180-9.
5. Kaufman T, Magosevich D, Moreno MC, Guzman MA, D'Atri LP, Carestia A, et al. Nucleosomes and neutrophil extracellular traps in septic and burn patients. Clin Immunol. 2017;183:254-62.

6. Corcoran RB, Chabner BA. Application of Cell-free DNA Analysis to Cancer Treatment. N Engl J Med. 2018;379(18):1754-65.

7. Leon SA, Shapiro B, Sklaroff DM, Yaros MJ. Free DNA in the Serum of Cancer Patients and the Effect of Therapy. Cancer Research. 1977;37(3):646-50.

8. Diehl F, Schmidt K, Choti MA, Romans K, Goodman S, Li M, et al. Circulating mutant DNA to assess tumor dynamics. Nature Medicine. 2008;14(9):985-90.

9. Luger K. Structure and dynamic behavior of nucleosomes. Curr Opin Genet Dev. 2003;13(2):127-35.

10. Bauden M, Pamart D, Ansari D, Herzog M, Eccleston M, Micallef J, et al. Circulating nucleosomes as epigenetic biomarkers in pancreatic cancer. Clin Epigenetics. 2015;7:106.

11. Rahier JF, Druez A, Faugeras L, Martinet JP, Gehenot M, Josseaux E, et al. Circulating nucleosomes as new blood-based biomarkers for detection of colorectal cancer. Clin Epigenetics. 2017:9:53.

12. Rasmussen L, Christensen IJ, Herzog M, Micallef J, Nielsen HJ, Danish Collaborative Group on Early Detection of Colorectal C. Circulating cell-free nucleosomes as biomarkers for early detection of colorectal cancer. Oncotarget. 2018;9(12):10247-58.

13. Cristiano S, Leal A, Phallen J, Fiksel J, Adleff V, Bruhm DC, et al. Genomewide cell-free DNA fragmentation in patients with cancer. Nature. 2019; 570(7761):385-9.

14. Letendre JA, Goggs R. Determining prognosis in canine sepsis by bedside measurement of cell-free DNA and nucleosomes. J Vet Emerg Crit Care (San Antonio). 2018;28(6):503-11.

15. Letendre JA, Goggs R. Concentrations of Plasma Nucleosomes but Not CellFree DNA Are Prognostic in Dogs Following Trauma. Front Vet Sci. 2018;5: 180.

16. Wilson-Robles H, Miller T, Jarvis J, Terrell J, Dewsbury N, Kelly T, et al. Evaluation of nucleosome concentrations in healthy dogs and dogs with cancer. PLoS One. 2020;15(8):e0236228.

17. Lamerato-Kozicki AR, Helm KM, Jubala CM, Cutter GC, Modiano JF. Canine hemangiosarcoma originates from hematopoietic precursors with potential for endothelial differentiation. Exp Hematol. 2006:34(7):870-8.

18. Bastianello SS. A survey of neoplasia in domestic species over a 40-year period from 1935 to 1974 in the Republic of South Africa. III. Tumours occurring in pigs and goats. Onderstepoort J Vet Res. 1983;50(1):25-8.

19. MacVean DW, Monlux AW, Anderson PS, Jr., Silberg SL, Roszel JF. Frequency of canine and feline tumors in a defined population. Vet Pathol. 1978;15(6): 700-15.

20. Spangler WL, Culbertson MR. Prevalence, type, and importance of splenic diseases in dogs: 1,480 cases (1985-1989). J Am Vet Med Assoc. 1992;200(6): 829-34.

21. Spangler WL, Kass PH. Pathologic factors affecting postsplenectomy survival in dogs. J Vet Intern Med. 1997;11(3):166-71.

22. Brown NO, Patnaik AK, MacEwen EG. Canine hemangiosarcoma: retrospective analysis of 104 cases. J Am Vet Med Assoc. 1985;186(1):56-8.

23. Prymak C, McKee LJ, Goldschmidt MH, Glickman LT. Epidemiologic, clinical, pathologic, and prognostic characteristics of splenic hemangiosarcoma and splenic hematoma in dogs: 217 cases (1985). J Am Vet Med Assoc. 1988; 193(6):706-12.

24. Aronsohn MG, Dubiel B, Roberts B, Powers BE. Prognosis for Acute Nontraumatic Hemoperitoneum in the Dog: A Retrospective Analysis of 60 Cases (2003-2006). J Am Anim Hosp Assoc. 2009;45(2):72-7.

25. Wendelburg KM, Price LL, Burgess KE, Lyons JA, Lew FH, Berg J. Survival time of dogs with splenic hemangiosarcoma treated by splenectomy with or without adjuvant chemotherapy: 208 cases (2001-2012). J Am Vet Med Assoc. 2015;247(4):393-403.

26. Krogh AKH, Lyngby JG, Biørnvad CR, Nielsen LN. Presence of nucleosomes in plasma and increased thrombin generation in dogs with acute and chronic gastroenteropathies. Res Vet Sci. 2021;135:504-10. https://doi.org/1 0.1016/.jvsc.2020.11.012

27. García-Olmo D, García-Olmo DC, Ontañón J, Martinez E, Vallejo M. Tumor DNA circulating in the plasma might play a role in metastasis. The hypothesis of the genometastasis. Histol Histopathol. 1999;14(4):1159-64.

28. Tanner JE. Nucleosomes activate NF-kappaB in endothelial cells for induction of the proangiogenic cytokine IL-8. Int J Cancer. 2004;112(1):155-60.

29. Le Lann-Terrisse AD, Fournié GJ, Benoist H. Nucleosome-dependent escape of tumor cells from natural-killer-mediated lysis: nucleosomes are taken up 
by target cells and act at a postconjugation level. Cancer Immunol Immunother. 1997:43(6):337-44.

30. Holdenrieder S, Stieber P, Bodenmüller H, Busch M, Fertig G, Fürst H, et al. Nucleosomes in serum of patients with benign and malignant diseases. Int J Cancer. 2001;95(2):114-20.

31. Holdenrieder S, Stieber P, Bodenmüller H, Busch M, Von Pawel J, Schalhorn A, et al. Circulating nucleosomes in serum. Ann N Y Acad Sci. 2001;945:93-102.

32. Holdenrieder S, Stieber P. Therapy control in oncology by circulating nucleosomes. Ann N Y Acad Sci. 2004;1022:211-6.

33. Holdenrieder S, von Pawel J, Dankelmann E, Duell T, Faderl B, Markus A, et al. Nucleosomes, ProGRP, NSE, CYFRA 21 - 1, and CEA in monitoring firstline chemotherapy of small cell lung cancer. Clin Cancer Res. 2008;14(23): 7813-21.

34. Holdenrieder S, von Pawel J, Dankelmann E, Duell T, Faderl B, Markus A, et al. Nucleosomes and CYFRA 21 - 1 indicate tumor response after one cycle of chemotherapy in recurrent non-small cell lung cancer. Lung Cancer. 2009:63(1):128-35.

35. Trejo-Becerril C, Perez-Cardenas E, Trevino-Cuevas H, Taja-Chayeb L, GarciaLopez P, Segura-Pacheco B, et al. Circulating nucleosomes and response to chemotherapy: an in vitro, in vivo and clinical study on cervical cancer patients. Int J Cancer. 2003;104(6):663-8.

36. Mueller S, Holdenrieder S, Stieber P, Haferlach T, Schalhorn A, Braess J, et al. Early prediction of therapy response in patients with acute myeloid leukemia by nucleosomal DNA fragments. BMC Cancer. 2006;6:143.

37. Holdenrieder S, Stieber P, J VONP, Raith H, Nagel D, Feldmann K, et al. Early and specific prediction of the therapeutic efficacy in non-small cell lung cancer patients by nucleosomal DNA and cytokeratin-19 fragments. Ann N Y Acad Sci. 2006;1075:244-57.

38. Holdenrieder S, Stieber P, von Pawel J, Raith H, Nagel D, Feldmann K, et al. Circulating nucleosomes predict the response to chemotherapy in patients with advanced non-small cell lung cancer. Clin Cancer Res. 2004;10(18 Pt 1): 5981-7.

39. Selting KA, Ringold R, Husbands B, Pithua PO. Thymidine Kinase Type 1 and C-Reactive Protein Concentrations in Dogs with Spontaneously Occurring Cancer. J Vet Intern Med. 2016;30(4):1159-66.

40. Nakamura M, Takahashi M, Ohno K, Koshino A, Nakashima K, Setoguchi A, et al. C-reactive protein concentration in dogs with various diseases. J Vet Med Sci. 2008;70(2):127-31.

41. Thamm DH, Kamstock DA, Sharp CR, Johnson SI, Mazzaferro E, Herold LV, et al. Elevated serum thymidine kinase activity in canine splenic hemangiosarcoma*. Vet Comp Oncol. 2012;10(4):292-302.

42. Arimura Y, lkura M, Fujita R, Noda M, Kobayashi W, Horikoshi N, et al. Cancer-associated mutations of histones H2B, H3.1 and H2A.Z.1 affect the structure and stability of the nucleosome. Nucleic Acids Res. 2018;46(19): 10007-18.

43. Batschinski K, Nobre A, Vargas-Mendez E, Tedardi MV, Cirillo J, Cestari G, et al. Canine visceral hemangiosarcoma treated with surgery alone or surgery and doxorubicin: 37 cases (2005-2014). Can Vet J. 2018;59(9):96772.

44. Team RC. R: A language and environment for statistical computing. 2017.

45. Xavier Robin NT, Alexandre Hainard, et al. pROC: an open-source package for $\mathrm{R}$ and $\mathrm{S}+$ to analyze and compare ROC curves. BMC Bioinformatics. $2011 ; 7(77)$.

\section{Publisher's Note}

Springer Nature remains neutral with regard to jurisdictional claims in published maps and institutional affiliations.

Ready to submit your research? Choose BMC and benefit from:

- fast, convenient online submission

- thorough peer review by experienced researchers in your field

- rapid publication on acceptance

- support for research data, including large and complex data types

- gold Open Access which fosters wider collaboration and increased citations

- maximum visibility for your research: over $100 \mathrm{M}$ website views per year

At BMC, research is always in progress.

Learn more biomedcentral.com/submissions 